\title{
The Effect of Waste Mineral Powders on the Structure of Air Voids in Low-Strength Air-Entrained Concrete Floor Screeds
}

\author{
Łukasz Sadowski ${ }^{1} \cdot$ Damian Stefaniuk $^{1} \cdot$ Magdalena Różańska $^{2} \cdot$ Ireneusz Usydus $^{2} \cdot$ Jacek Szymanowski $^{1}$
}

Received: 5 October 2017 / Accepted: 20 August 2018 / Published online: 23 August 2018

(c) The Author(s) 2018

\begin{abstract}
The purpose of the article is to present the results of the evaluation of the structure of air voids in low-strength air-entrained concrete (AEC) floor screeds modified with mineral powders sourced from industrial wastes. Quartz-feldspar and basalt powders were selected for aggregate quarry waste to replace $10 \%, 20 \%$, and $30 \%$ of the mass of the binder. The principal aim of this study is to investigate the effect of adding selected powders on the structure of the air voids in AEC floor screeds. The structure of the air voids was measured using X-ray micro computed tomography (micro-CT). In the analysis, two methodologically different approaches were used, i.e., the volume-equivalent sphere diameter of the air voids and the local structure thickness of the air voids. It was seen that the structure of the air voids in the modified AEC floor screeds is different when compared to the reference AEC floor screeds without powders and non-AEC screeds. It was also shown that the microstructure differs for different amounts and types of used mineral powder.
\end{abstract}

Keywords Air-entrainment $\cdot$ Screeds $\cdot$ Concrete $\cdot$ Mineral powders $\cdot$ Cement $\cdot$ Structure of air voids

\section{Statement of Novelty}

Mineral industrial wastes can be incorporated in airentrained concrete (AEC) floor screeds. These wastes are sourced from aggregate quarries as the byproducts from the aggregate production. There are no studies in literature that evaluate the structure of air voids in AEC floor screeds modified using this kind of wastes. To fill this knowledge gap, the paper aims to investigate the structure of air voids in AEC modified using waste mineral powders. Quartz-feldspar and basalt powders were selected. To characterize the structure of air voids the micro-CT was used. The principal aim of this study is to understand more clearly the effect of adding selected mineral powders on the structure of the air voids in AEC floor screeds.

Łukasz Sadowski

lukasz.sadowski@pwr.edu.pl

1 Faculty of Civil Engineering, Wrocław University of Science and Technology, Wybrzeże Wyspiańskiego 27, 50-370 Wrocław, Poland

2 The State School of Higher Education in Chełm, ul. Pocztowa 54, 22-100 Chełm, Poland

\section{Introduction}

Floor screed is a thin, top layer of material, poured in site on the top of the concrete substrate or insulation. On the top of it other finishing materials can be applied (e.g., ceramic tiles, epoxy resin). Sometimes it can be left bare to achieve a raw effect. Recently, the floor screeds are being more often used as exterior substrates in terraces or balconies, etc. This kind of external floor screeds are more frequently subjected to frost actions. To prevent it, they are more often being made by using the material containing air entraining admixture (AEA) and coarse aggregate up to $8 \mathrm{~mm}$ maximum aggregate size. However, due to the lack of space for installation of hand-held surface vibration machine, such kind of screeds is not usually specially compacted. Floor screeds are only patch grabbed to ensure flat surface for the application of next finishing layer (Fig. 1). In this case the compressive strength $\left(f_{\mathrm{c}}\right)$ of such a floor screed is usually lower than $15 \mathrm{MPa}$.

AEA is added to AEC floor screeds to reduce the freeze thaw damage [1]. Because, as pointed out in [2], the innovations in civil engineering can't be done without considering the sustainable development, the mineral industrial wastes are being recently more popular as the additives in AEC screeds. For example Zobal et al. [3] used commonly known 


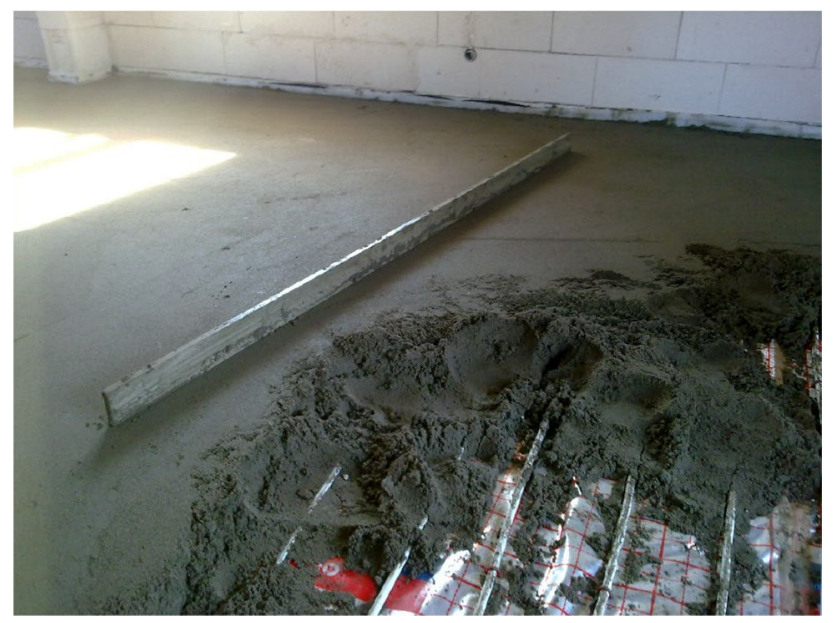

Fig. 1 Exemplary view of concrete floor screed during construction

and popular fly ash to improve the frost resistance of concrete floor screeds. This kind of wastes can be also sourced from aggregate quarries as the byproduct from the production [4-6]. The chemical composition and particle size make this byproduct an attractive additive that can be used in durable and sustainable cement-based matrices [7-9].

Sensible use of wastes will reduce cost of production [10-15]. Recently, more often these attempts are related to concrete floor screeds. For example, Bergmans et al. [16] used the recycled autoclaved aerated concrete sourced from demolition waste as a replacement of sand in floor screeds. On the other hand Moreira et al. [17] used cork granules for this purpose. The application of powders has recently grown very fast [18]. As shown by [19-21], attempts to modify concrete with mineral powders are effective. However, they generally result in a deterioration of their compressive strength. Popek et al. [22] indicated that the application of quartz mineral powder in concrete is accompanied by an increase in abrasion resistance. Tayeh et al. [23] drew attention to the fact that a decreasing porosity of concrete is beneficial. Thus, the addition of marble powder, metakaolin, silica fume, and fly ash are useful for this purpose.

However, the compressive strength of the AEC floor screed is not always a critical parameter. Most of the AEC floor screeds have a higher compressive strength than required in design. An important factor for the durability of low-strength air-entrained concrete (AEC) floor screeds is the structure of air voids. As a general rule of thumb, a $1 \%$ increase in air content results in about a 5\% decrease in the compressive strength of AEC [24]. As pointed out by Bogas et al. [25], the use of AEA has a slightly beneficial effect on high-strength concretes. According to Ramezanianpour et al. [26], the application of AEA increased water permeability and capillary absorption. Air voids can be seen to be the very important with regards to AEC [27-30]. Piasta and Sikora [31] pointed out that higher shrinkage might be due to air voids. Thus, knowledge of the distribution, and number and shape of the air voids in hardened AEC floor screeds are important.

Due to a high air-void content and low compressive strength, it is difficult to correctly characterize the volume fraction of air voids in AEC floor screeds. Evaluation of the air voids in AEC floor screeds remains a challenging task [32]. It has to be noted, that according to ASTM C 457 [33] air voids have a diameter greater than $2 \mu \mathrm{m}$. On the other side, according to ASTM C 125 [34] entrapped air voids in concrete have a diameter of more than $1 \mathrm{~mm}$. Usually they have irregular shape. The diameter of typical entrained air voids is in the range of $10-1000 \mu \mathrm{m}$. The shape of these air voids is similar to a spherical shape. Research performed by Łaźniewska-Piekarczyk [35] proves that the size and distribution of the air voids depend on the type of used superplasticizer.

Usually, scanning electron microscopy (SEM) is used for the evaluation of structure of air voids in concrete. However, SEM requires a sample to be specifically prepared, sliced, and etched to view of the internal structure of the material. As pointed out by Hubler et al. [23] this kind of sample preparation mainly causes damage to the softer phases and also fine scale features. These steps may especially be a challenge to use them for low-strength AEC floor screeds with high porosity. Thus, for the stabilization of samples made of this kind of concrete, it is necessary to embed the material into a stiff polymer before preparation (usually an impregnation in epoxy) and an exposure to high vacuum pressure conditions inside the chamber. Nevertheless, this process may have an impact on the microstructure of the investigated sample and consequently may influence the proper material's characterization [37]. Also, one of the major limitations of SEM is the lack of access to real three-dimensional (3D) when trying to extract quantitative information on structure of pores in porous material [37]. Recently, the SEM imaging allows viewing 3D microstructure of the AEC by drilling into the sample below. Then, the 3D and 2D images are sequentially combining at various depths. Nevertheless, the drilling is not precise in case of depth of the sample. For low-strength and porous concretes (such as the AEC floor screeds) the proper preparation of the sample for SEM analysis may not be possible. It has been highlighted by Kashani et al. [38], who used SEM-based results only as an indication rather than accurate elemental analysis of the microstructure of the rubberized lightweight cellular concrete. As concluded, [39] to obtain the total air-voids range, other techniques (such as light optical microscopy, SEM, transmission electron microscopy [40, 41], RapidAir [42] and more methods [43]) may be complementarily used. Currently, the evaluation of the pore structure of AEC can be performed using more advanced methods $[44,45]$. One promising method is X-ray 
micro-computed tomography (micro-CT). X-ray micro-CT can provide information on the size and distribution of air voids [46-51]. Recently, X-ray micro-CT is popular for the evaluation of cement-based materials [49, 52-55], especially with high porosity, e.g., foamed concrete [56]. There are no studies in literature that evaluate the structure of air voids in AEC floor screeds modified using mineral powders sourced from industrial wastes.

To fill this knowledge gap, the paper aims to investigate the structure of air voids in AEC floor screeds modified using waste mineral powders. Quartz-feldspar and basalt powders were selected to replace $10 \%, 20 \%$, and $30 \%$ of the mass of the cement. To characterize the structure of air voids in AEC screeds, SEM and X-ray micro-CT were used. However, the first technique was used only for preliminary tests, while the latter one was used for main study and to a much greater extent. The principal aim of this study is to better understand the effect of adding selected waste mineral powders on the structure of the air voids in AEC floor screeds. The results are supplemented with common physical and mechanical properties of the investigated samples.

\section{Experimental Procedure}

\section{Materials}

According to EN 12,620, the concrete was made of coarse aggregate with a maximum grain size $D_{\max }$ of $8 \mathrm{~mm}$ and a density of $2.62 \mathrm{mg} / \mathrm{m}^{3}$ (mineral mine "Margo", Mietkow, Poland) and also fine aggregate in the form of river sand with a maximum grain size $D_{\max }$ of $2 \mathrm{~mm}$ and a density of $2.62 \mathrm{mg} / \mathrm{m}^{3}$ (mineral mine "Margo", Mietkow, Poland). The sieve analysis of the used aggregates is presented in Fig. 2.
Tap water was used as the batch water (according to EN 1008). The water absorption of the aggregate was $1.5 \%$. The aggregate was pre-dried. The amount of water needed to bring it to a saturated surface-dry condition was determined. Then, the determined amount has been added to the batch water. The AEC floor screeds was cast with CEM I 42.5 R (according to EN197-1:2000). A water-binder ratio amounted to $0.40 .0 .11 \mathrm{~kg} / \mathrm{m}^{3}(16 \mathrm{~g}$ per $50 \mathrm{~kg}$ of the cement mass) of the AEA in the form of plasticizer Qmix DH (DMB Tomasz Dembczynski, Warsaw, Poland) was applied. The AEA is made based on dodecylsulfonic acid sodium salt. It was used to aerate and achieve a workable condition of the fresh concrete mixture. It is helpful in reducing shrinkage and surface microcracks. It is also helpful in increasing water- and frost resistance. Two types of waste mineral powders were used: quartz-feldspar (F) and basalt (B). The quartz-feldspar powder has been sourced from mineral mine Strzeblowskie Kopalnie Surowców Mineralnych (SKSM), Sobótka, Poland [58]. Quartz-feldspar powder has been produced by the SKSM from its own raw material by iron-free grinding and air classification. This product is currently available on the market. But its application is limited to ceramics and has not been used for the cement-based materials. This powder has not been specially prepared before the application in AEC floor screed. However, certain deviations of the product parameters due to the variability of the natural raw material were taken into account. On the other hand, the basalt powder has been taken from mineral mine PGP Bazalt, Wilków, Poland [59]. Basalt powder has been produced by the PGP Bazalt from its own raw material by iron-free grinding and air classification. This powder is not currently available on the market. The sieve analysis of the cement (CEM) and selected mineral powders is
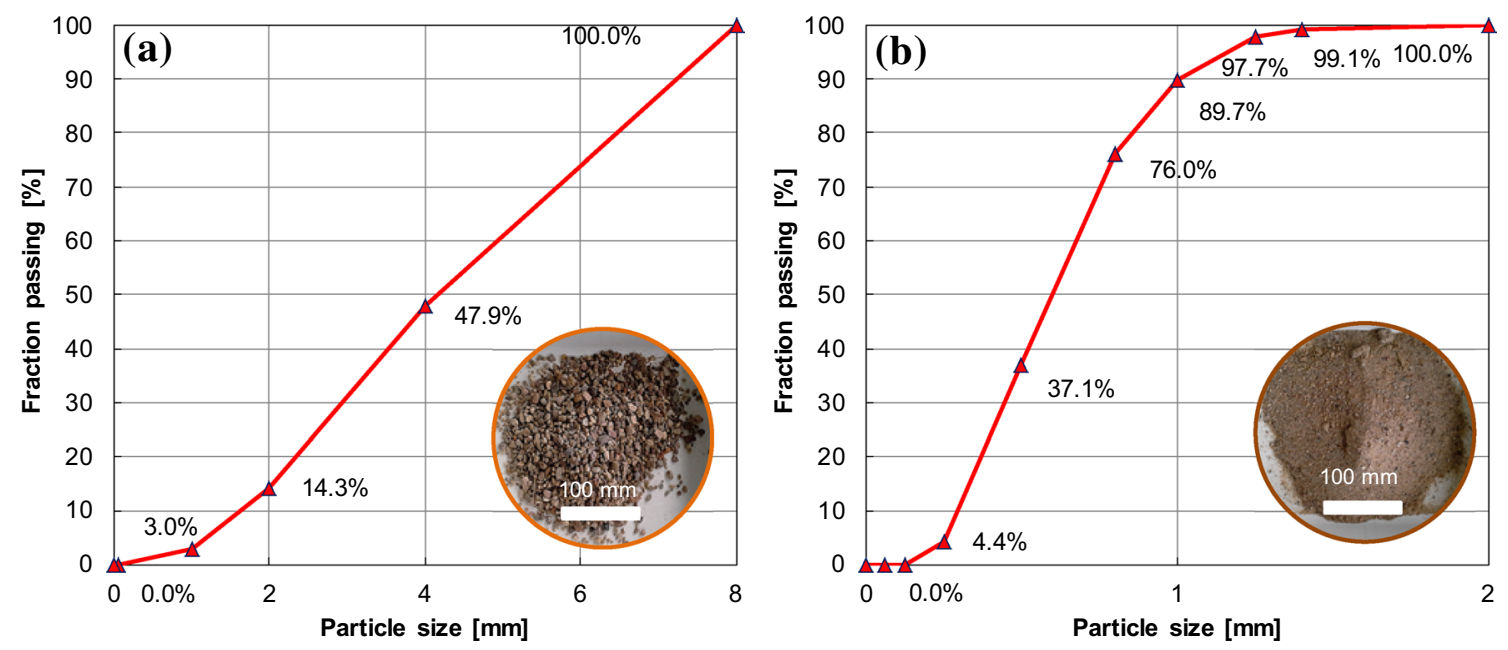

Fig. 2 Sieve analysis of aggregates: $\mathbf{a}$ coarse, $\mathbf{b}$ fine 


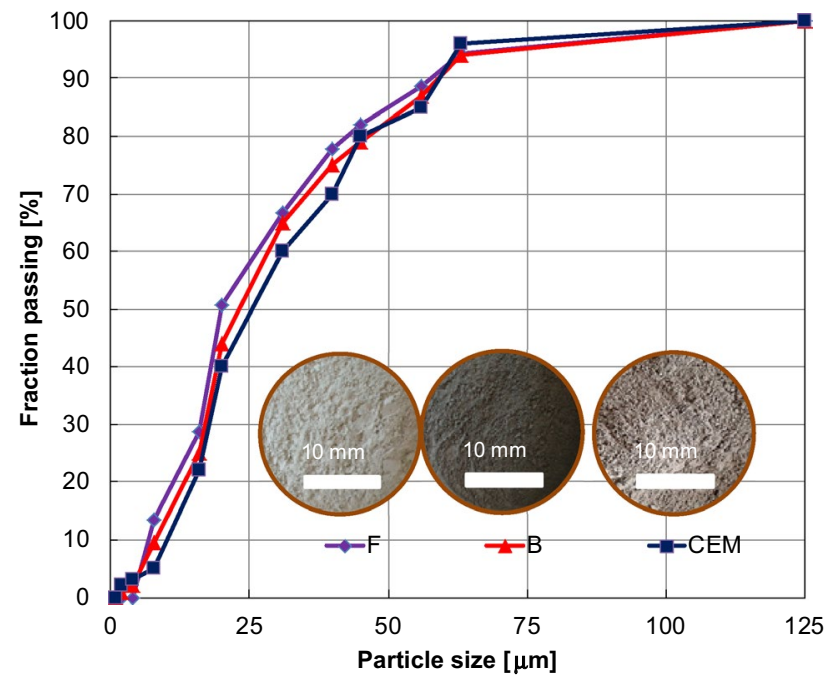

Fig. 3 Sieve analysis of cement and selected mineral powders

Table 1 Chemical composition of cement CEM I $42.5 \mathrm{R}$ and selected mineral powders (in $\%$ of weight)

\begin{tabular}{llll}
\hline Particle & Portland cement & $\begin{array}{l}\text { Quartz-feldspar } \\
(\mathrm{F})\end{array}$ & Basalt (B) \\
\hline $\mathrm{SiO}_{2}$ & 19.0 & 74.10 & 49.5 \\
$\mathrm{Al}_{2} \mathrm{O}_{3}$ & 4.90 & 13.25 & 15 \\
$\mathrm{Fe}_{2} \mathrm{O}_{3}$ & 2.70 & 0.35 & 3.7 \\
$\mathrm{TiO}_{2}$ & - & 0.05 & - \\
$\mathrm{CaO}$ & 63.90 & 0.45 & 9.6 \\
$\mathrm{MgO}$ & 1.30 & 0.50 & 6.8 \\
$\mathrm{SO}_{3}$ & 2.70 & - & - \\
$\mathrm{Na}_{2} \mathrm{O}$ & 0.14 & 6.10 & 2.9 \\
$\mathrm{~K}_{2} \mathrm{O}$ & 0.82 & 5.20 & 1.2 \\
$\mathrm{Cl}$ & 0.072 & - & - \\
$\mathrm{P}_{2} \mathrm{O}_{5}$ & - & - & 0.4 \\
Other & 4.468 & 0 & 10.9 \\
\hline
\end{tabular}

presented in Fig. 3. In turn, the chemical composition of cement CEM I 42.5 $\mathrm{R}$ and these admixtures is presented in Table 1.

Eight concrete mixes were prepared according to the composition of concrete mixes given in Table 2. The mixture without AEA was prepared (0) together with a reference mixture without waste mineral powders (R). The mixtures with waste mineral powders were prepared by replacing $10 \%, 20 \%$, and $30 \%$ of the cement mass.

Preparation of the mixes was conducted in controlled laboratory conditions. The raw materials were batched by mass. Then, they were mixed together using a pan mixer. The aggregate, cement, and waste mineral powder were mixed for about 2 min (until they were homogenous). AEA was added to the initial mixing water. Then AEA was gradually added to the mix. The obtained concrete was mixed for about $3 \mathrm{~min}$. The samples were not compacted, but only patch grabbed as usually in the case of floor screeds. The method of preparation was the same for all series of concrete.

\section{Macroscale Laboratory Tests}

The concrete mixtures were filled into three gang moulds with a size of $150 \times 150 \times 150 \mathrm{~mm}$ to obtain the compressive strength $\left(f_{\mathrm{c}}\right)$, three gang moulds with a size of $150 \times 150 \times 600 \mathrm{~mm}$ to obtain the tensile strength $\left(f_{\mathrm{ct}}\right)$ and three gang moulds with a size of $40 \times 40 \times 160 \mathrm{~mm}$ for testing its microscopic properties. The concrete inside the gang moulds has been compacted in three layers. For this purpose a vibrating table with adjustable intensity and duration has been used. The compacted moulds were then covered with plastic foil. They were wet hessian until an age of $24 \mathrm{~h}$. After $48 \mathrm{~h}$, they were all demoulded. Then, they were kept at an air temperature of $20{ }^{\circ} \mathrm{C}\left( \pm 2{ }^{\circ} \mathrm{C}\right)$ and relative air humidity of $60 \%( \pm 5 \%)$. After 28 days, three samples were bent in a testing machine to determine their tensile strength. Subsequently, the three samples were used to test compressive
Table 2 Composition of the concrete mixes

\begin{tabular}{llllllll}
\hline $\begin{array}{l}\text { Series of } \\
\text { concrete }\end{array}$ & \multicolumn{6}{l}{ Components of the mixes $\left[\mathrm{kg} / \mathrm{m}^{3}\right]$} \\
\cline { 2 - 7 } & Cement & $\begin{array}{l}\text { Type of mineral } \\
\text { powder }\end{array}$ & Water & Fine aggregate & Coarse aggregate & Qmix DH \\
\cline { 3 - 7 } & & & & & & \\
\hline 0 & 352.0 & 0 & 0 & 141 & 676 & 1205 & 0 \\
R & 352.0 & 0 & 0 & 141 & 676 & 1205 & 1.10 \\
F10 & 316.8 & 35.2 & 0 & 141 & 676 & 1205 & 1.10 \\
F20 & 281.6 & 70.4 & 0 & 141 & 676 & 1205 & 1.10 \\
F30 & 246.4 & 105.6 & 0 & 141 & 676 & 1205 & 1.10 \\
B10 & 316.8 & 0 & 35.2 & 141 & 676 & 1205 & 1.10 \\
B20 & 281.6 & 0 & 70.4 & 141 & 676 & 1205 & 1.10 \\
B30 & 246.4 & 0 & 105.6 & 141 & 676 & 1205 & \\
\hline
\end{tabular}


strength (according to EN 12390-3). The final results were reported in the form of the average value of three specimens. Then, after 28 days three bars from each type of concrete mix was weighed, then immersed in water and kept in it for 7 days so the pores were filled. After that the samples were weighed twice: once in air and secondly in water. All the samples were then dried at the temperature of $105^{\circ} \mathrm{C}$ for 7 days. All dry samples were weighed. Figure 4 presents the view of dry hardened concrete bars together with hardened concrete bars immersed in the water. Then, the bulk density $\left(\rho_{\mathrm{b}}\right)$, watertightness $(w)$, and total porosity $\left(P_{\mathrm{t}}\right)$ were calculated according to:

$\rho_{\mathrm{b}}=\frac{m_{\mathrm{d}}}{m_{\mathrm{s}}-m_{\mathrm{h}}} \times \rho_{\mathrm{h}}$,

$w=\frac{\rho_{\mathrm{b}}}{\rho} \times 100 \%$,

$a=\frac{m_{\mathrm{s}}-m_{\mathrm{d}}}{m_{\mathrm{d}}} \times 100 \%$,

$P_{\mathrm{t}}=(1-w) \times 100 \%$,

where $\rho$ is the density, $m_{\mathrm{o}}$ is the initial mass of concrete, $m_{\mathrm{s}}$ is the mass of saturated concrete in air, $m_{\mathrm{h}}$ is the mass of saturated concrete in water and $m_{\mathrm{d}}$ is the mass of dry concrete.

\section{Microscale Laboratory Tests}

At first, scanning electron microscope (SEM) JEOL JSM6610A equipped with a tungsten hairpin filament was used for preliminary tests. Nevertheless, despite the extremely high resolution of SEM imaging, the characteristics of the samples under investigation forced the authors to use a different technique, i.e., X-ray micro-CT (Fig. 5). For this purpose, samples of $40 \times 40 \times 160 \mathrm{~mm}$ after 28 days of curing, from each series of concretes the hardened AEC floor screeds, were used.

The apparatus used for obtaining the 3D images of the AEC floor screeds samples' air voids structure was an $\mathrm{X}$-ray micro-CT scanner GE phoenix vltomelxs (General Electric Measurements, United States), presented in Fig. 5. The detector type GE DXR250RT was used at a distance of $800 \mathrm{~mm}$ from the source. The optimal scanning parameters were found after couple trial scans. Based on the scans, the energy of the incident X-ray beam was set to $240 \mathrm{kV} / 320 \mathrm{~W}$. In addition, a $0.5 \mathrm{~mm} \mathrm{Cu}$ filter as well as a high-power $\mathrm{X}$-ray microfocus tube was used. A good balance between X-ray penetration and absorption contrast has been obtained for
Fig. 4 View of a dry hardened concrete bars, $\mathbf{b}$ hardened concrete bars immersed in water (a)

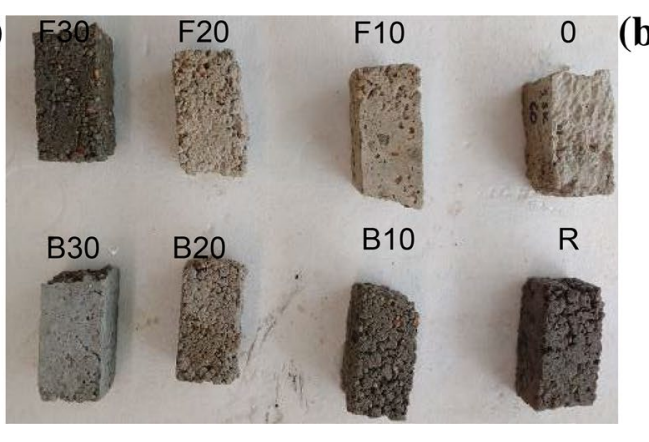

(b)

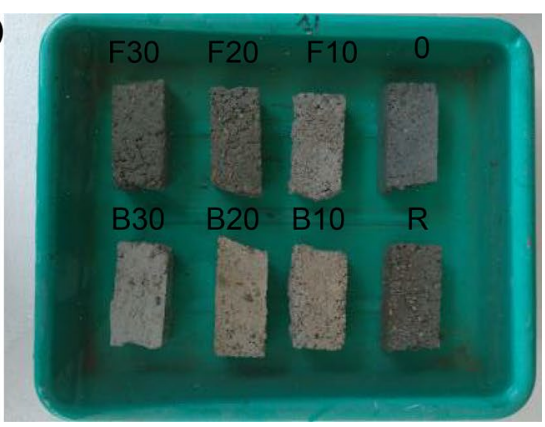

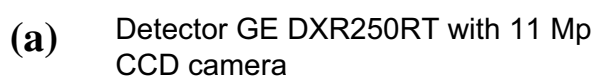

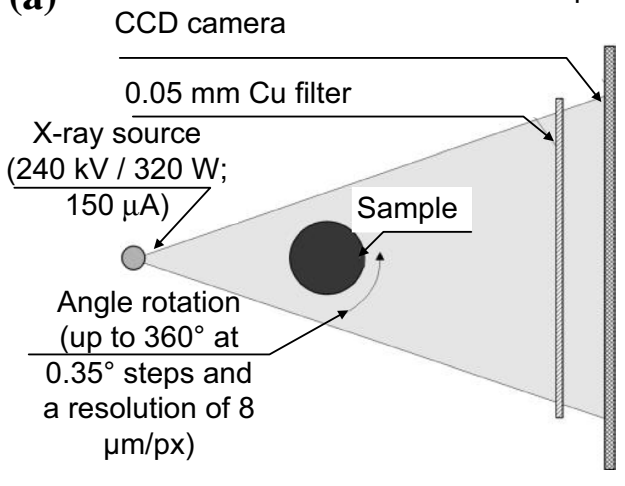

(b)

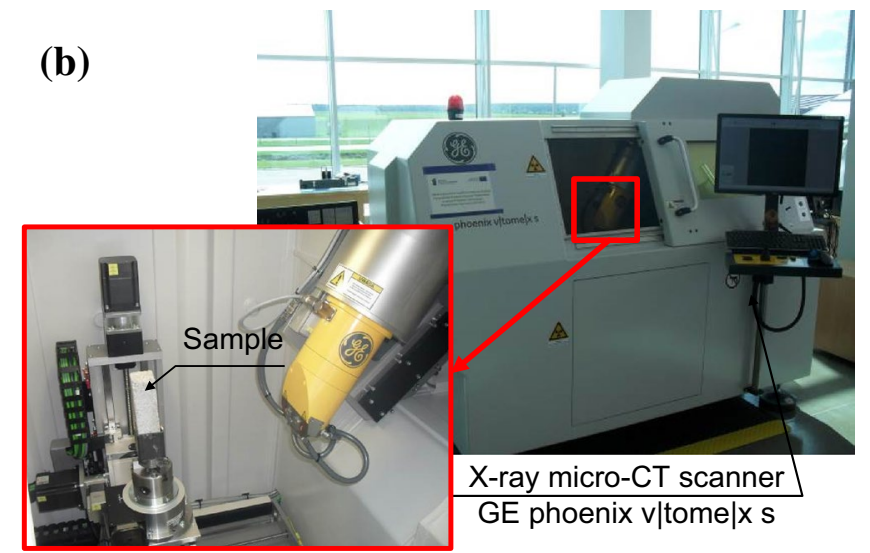

Fig. 5 X-ray micro-CT: a scheme of the test and $\mathbf{b}$ view of the scanner with a sample placed on a tripod 
the applied energy. An angle rotation of up to $360^{\circ}$ was adopted. The resolution of $65 \mu \mathrm{m} / \mathrm{px}$ (micrometre per pixel) has been obtained. Using this resolution, only a fraction of the entrained air voids larger than $130 \mu \mathrm{m}$ will be characterized. Also the size of the sample should be 5-10 times larger than the maximum diameter of aggregate. Therefore, scanning concrete is more challenging in contrast to cement paste, where there is no aggregate and the particles are much smaller [57]. Because of these limitations, the X-ray micro$\mathrm{CT}$ analysis has been used only as an indication rather than accurate elemental analysis of the effect of air-entrainment on the structure of air voids in AEC modified by mineral powders. $1300 \mathrm{X}$-ray projections for each scan were acquired. The exposure time was set to $333 \mathrm{~ms}$. Fully distortion-corrected 12-bit cooled charge coupled device (CCD) $11 \mathrm{Mp}$ X-ray fiber-optical camera was used to collect the raw projection data. Finally, each scan took approximately 25-30 min. A reconstruction of the obtained projections was made using phoenix datos|x CT software (General Electric Measurements, United States). After reconstruction, the 3D images were set together using 3D registration in CTVox version 3.2.0 3D (SkyScan, Kontich, Belgium).

Only a part of the 3D image was used for further analysis in CTAnalyser version 1.16 (SkyScan, Kontich, Belgium) in order to avoid the boundary effect [60]. The structure of air voids within a rectangular volume of interest (VOI) were evaluated. Thus, the same portion of each sample has been analyzed at identical positions from each 3D dataset and within selected VOIs. Then, the variations of the structure of the air voids in the tomographic images have been compared. The reconstruction was limited to a $470 \times 470 \times 770$-voxel subvolume for each sample. It corresponds to a rectangular cuboid. The volume of this cuboid amounted to $45 \mathrm{~cm}^{3}$ with a square base with sides of $30 \mathrm{~mm}$ and a height of $50 \mathrm{~mm}$. Taking into account the largest size of the air voids $(3 \mathrm{~mm})$ and aggregates $(8 \mathrm{~mm})$ the examined volumes can be considered representative.

The analysis of the structure of the air voids was preceded by filtering and binarization of the images. To reduce noise in the images, the Median filter was used twice with the radius of $1 \mathrm{px}$ in 3D. Because of a high contrast between air and solid phases, the air voids were segmented from a solid phase using manual global thresholding. This method produces "hard" threshold value to segment micro-CT volume [61]. The segmentation value was selected on the basis of visual similarity between corresponding $2 \mathrm{D}$ cross-sections of the gray scale and binarized images. The histogram of cement VOI of the exemplary sample (sample R) before and after filtering as well as the segmentation value on the histogram is presented in Fig. 6.

Based on it, the volume of void space $\left(V_{\mathrm{V}}\right)$ has been calculated. Thus, it was possible to evaluate the volume fraction of the air voids $(\varphi)$ as the ratio between $V_{\mathrm{V}}$ and the total

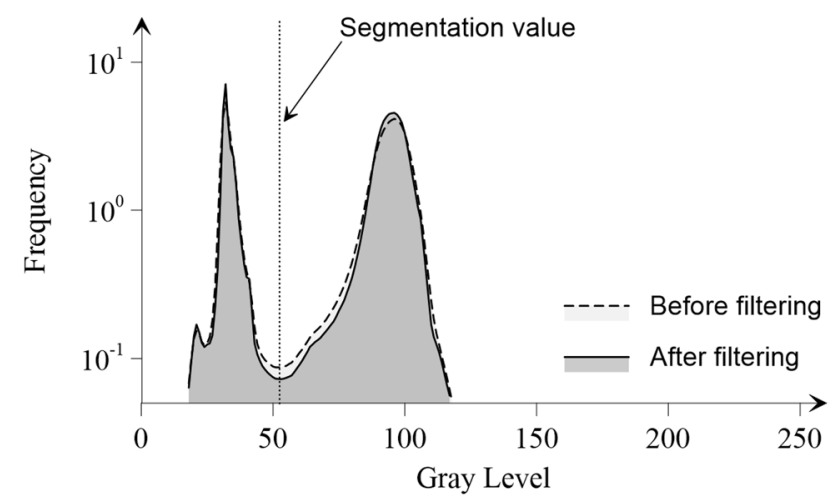

Fig. 6 The histogram of cement VOI before and after filtering

volume of material, including the solid and void components $\left(V_{\mathrm{T}}\right)$. This ratio can be defined by:

$\phi=\frac{V_{\mathrm{V}}}{V_{\mathrm{T}}}$.

The size of air voids was analyzed using two methodologically different approaches. First approach was related to the volume-equivalent sphere diameter of each air void. The second approach was based on the local structure thickness of the air voids. The volume-equivalent sphere diameter of the air voids is evaluated by replacing the volume of a given air void $\left(V_{\mathrm{p}}\right)$ by the equivalent perfect sphere of diameter $D_{\text {eq: }}$

$D_{\text {eq }}=\sqrt[3]{\frac{6 \cdot V_{\mathrm{p}}}{\pi}}$.

The measure of Deq defined by Eq. (2) accurately describes the size of spherical air voids. However, in a case of more complicated structure of air void space, where e.g., the air voids overlap, more sophisticated measures are needed. One of them is the local structure thickness. Let $\Omega \subset \mathrm{R} 3$ be the set of all points of the air void under consideration and $\tau$ $\in \Omega$ an arbitrary point in this air void. Then, according to Hildebrand and Rüegsegger [62] the local structure thickness $\operatorname{Dst}(\tau)$ can be defined as the largest diameter of sphere which is completely within the investigated air void and contains the point $\tau$ (note that, this point is not necessarily the center of the sphere):

$D_{\text {st }}(\tau)=2 \times \max (\{r \mid \tau \in \operatorname{sph}(x, r) \subseteq \Omega, x \in \Omega\})$,

where $\operatorname{sph}(x, r)$ is the set of points within a sphere with radius $r$ and center $x$. An advantage of the $D_{\text {st }}(\tau)$ measure is a minimum bias from the $3 \mathrm{D}$ orientation of the structure [63]. Note that, for an ideal spherical air void, $D_{\mathrm{eq}}$ and $D_{\mathrm{st}}(\tau)$ measurements lead to the same results.

The shape of air voids can be characterized using the sphericity $(\psi)$ measure. It is defined as the ratio between 
the surface area of a perfect sphere and the surface area of the considered air void [65]:

$\psi=\frac{\sqrt[3]{\pi} \cdot\left(6 \cdot V_{\mathrm{p}}\right)^{2 / 3}}{A_{\mathrm{p}}}$,

where Ap is the surface area of the air void. The value of $\psi$ can be in the range between 0 (fissure) and 1 (ideal sphere). For preliminary analysis, the roundness measure was also used due to the fact, that in the case of SEM imaging only $2 \mathrm{D}$ images were analyses. Its definition is analogous to the sphericity measure, with the difference, that it's the ratio between the circumference of a perfect circle and the considered air void.

All measurements presented above were calculated using CTAnalyser software (version 1.16.4.1, SkyScan, Kontich, Belgium). It should be noted that discrete pixels/voxels are used in the micro-CT images to represent continuum objects. Thus, errors due to discretization can include, e.g., the inaccurate description of curved air void boundaries and, as a consequence, the closing of small air voids [66]. Moreover, the effect of closing of air voids smaller than the resolution used for X-ray micro-CT scans results in lower values of $\varphi$ compared to the overall macroscopic porosity values. For each of the specimen three replicates tested for the microscale laboratory tests were done.

The detailed methodology applied for the evaluation of the structure of air voids in AEC floor screeds containing mineral powders sourced from industrial wastes using the $\mathrm{X}$-ray micro-CT technique is presented in Fig. 7.

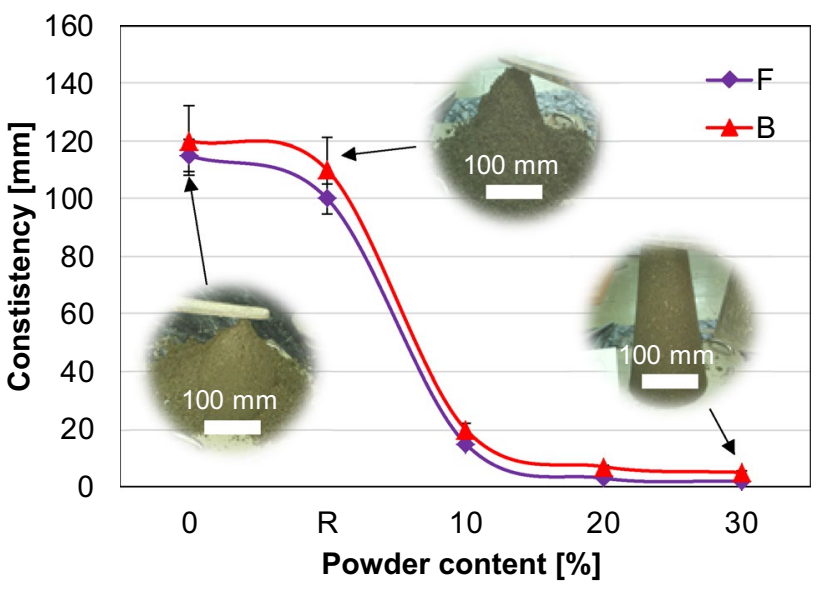

Fig. 8 Slump flow of the fresh concrete mixture

\section{Results and Discussion}

\section{Properties of Fresh Mixture}

As the fresh properties of concrete screeds are important in regulating material performance the slump flow has been measured. The results have been presented in Fig. 8 .

The obtained result is similar to the literature studies. For example Canbaz et al. [64] observed that, when aggregate was getting finer, the flow-ability of self-leveling screed was increased. In our study the flow-ability is low. It can be mainly due to the presence of coarse aggregate in the mixture. According to Fig. 8 it can be seen that the addition of waste mineral powders have a significant effect on the consistency of the fresh mixture.

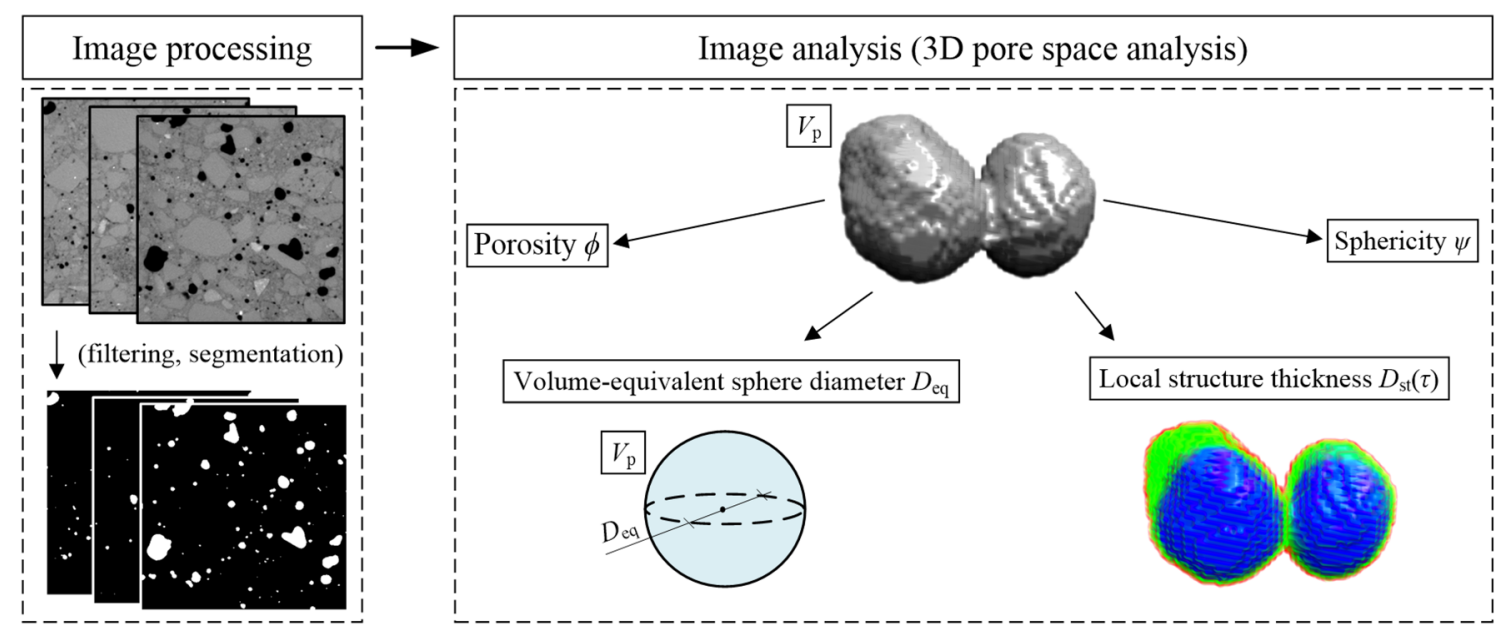

Fig. 7 The scheme of the applied methodology used for the evaluation of the structure of air voids in AEC floor screeds modified with mineral powders sourced from industrial wastes using the X-ray micro-CT method 


\section{Macroscale Laboratory Tests}

The average values of the selected physical and mechanical parameters of tested concretes obtained after 28 days of curing are presented in Table 3. It can be seen that AEA results in lower $f_{\mathrm{cm}}$ and $f_{\mathrm{ctm}}$ values of about $21 \%$ and $8.3 \%$, respectively, for sample $\mathrm{R}$ in comparison to sample 0 . It is also visible that the total porosity of the AEC reference sample (R) is higher than the sample without AEA. The application of both powders also causes in reduce the total porosity of the samples.

\section{Microscale Laboratory Tests}

Herein, the results of microscale laboratory tests using SEM and X-ray micro-CT methods are discussed. Firstly, the preliminary results of SEM imaging are presented for two samples, i.e., 0 and B30. Before samples preparation, the borders

Table 3 Average macroscopic values of selected physical and mechanical parameters of tested concretes obtained after 28 days of curing

\begin{tabular}{lllllll}
\hline $\begin{array}{l}\text { Series of } \\
\text { concrete }\end{array}$ & $\rho_{\mathrm{b}}\left[\mathrm{g} / \mathrm{cm}^{3}\right]$ & $a[\%]$ & $w[\%]$ & $P_{\mathrm{t}}[\%]$ & $f_{\mathrm{cm}}[\mathrm{MPa}]$ & $f_{\mathrm{ctm}}[\mathrm{MPa}]$ \\
\hline 0 & 2.18 & 5.37 & 78.31 & 11.77 & 37.55 & 5.63 \\
R & 2.05 & 8.99 & 71.62 & 18.02 & 29.73 & 5.16 \\
F10 & 2.02 & 7.76 & 72.66 & 15.78 & 10.93 & 1.95 \\
F20 & 1.98 & 8.65 & 70.45 & 17.05 & 9.85 & 1.64 \\
F30 & 1.97 & 9.41 & 70.11 & 18.48 & 7.67 & 1.48 \\
B10 & 2.01 & 8.42 & 71.78 & 16.93 & 11.40 & 2.11 \\
B20 & 2.03 & 7.65 & 72.85 & 15.61 & 9.07 & 2.81 \\
B30 & 2.02 & 8.38 & 71.99 & 16.89 & 8.13 & 1.41 \\
\hline
\end{tabular}
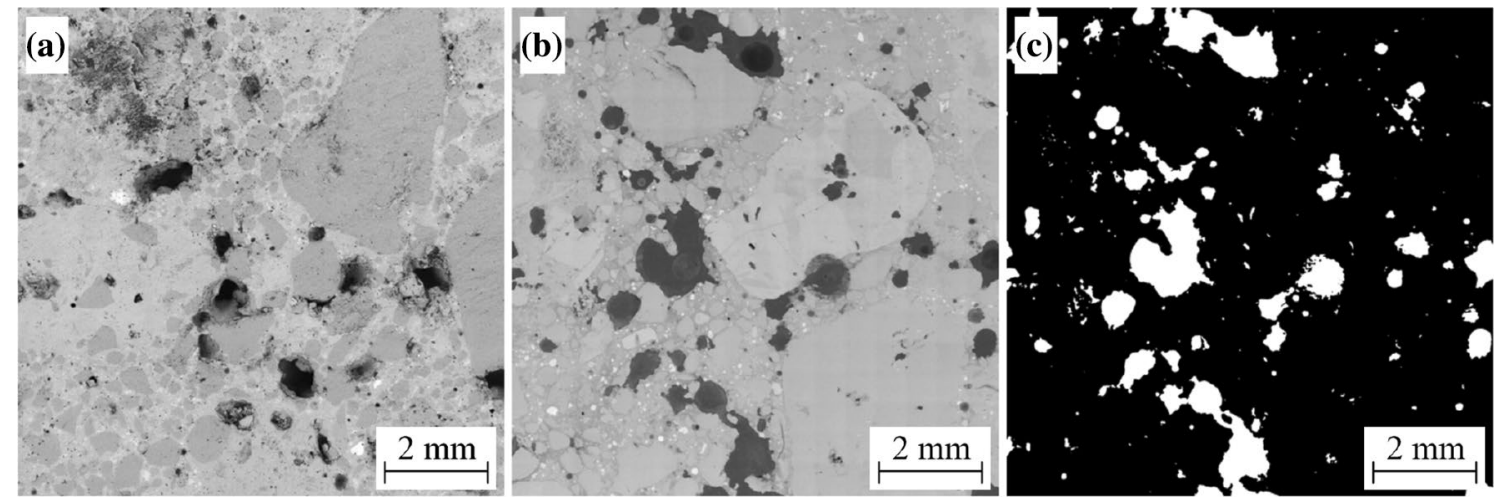

Fig. 9 2D microstructure views obtained by the SEM method for sample 0: a before sample preparation, $\mathbf{b}$ after immersing the sample in the resin and polishing the surface and $\mathbf{c}$ binarized image from $\mathbf{b}$
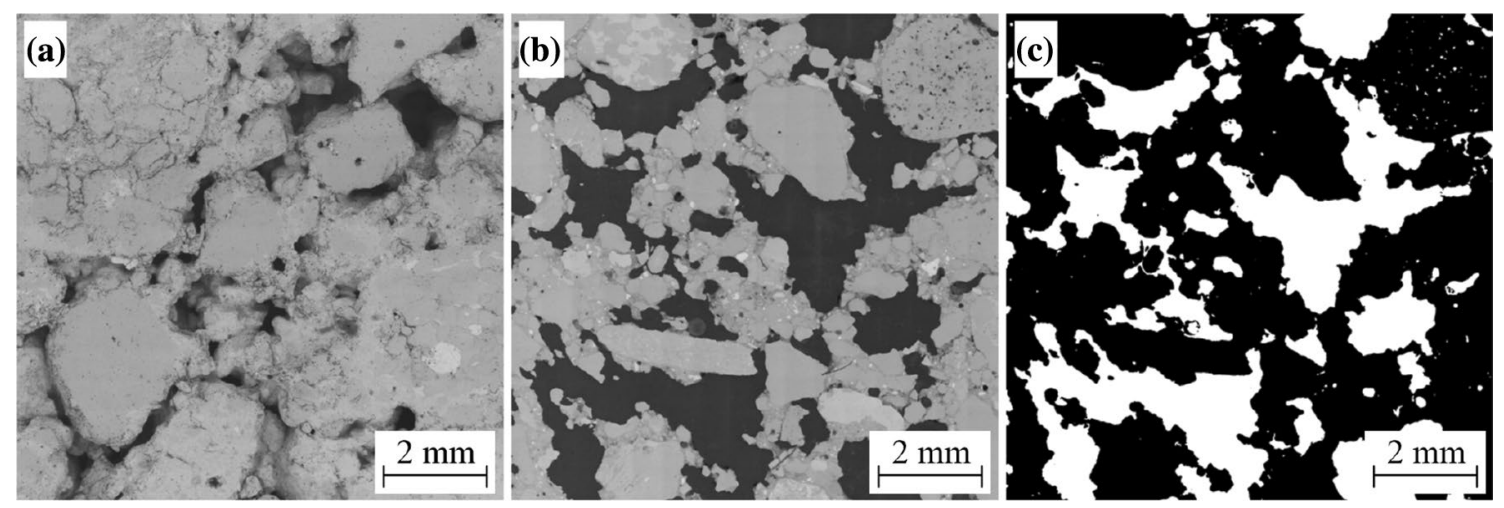

Fig. 10 2D microstructure views obtained by the SEM method for sample B30: a before sample preparation, $\mathbf{b}$ after immersing the sample in the resin and polishing the surface and $\mathbf{c}$ binarized image from $\mathbf{b}$ 
of air voids are not clear in the images (see Figs. 9a, 10a for sample 0 and B30, respectively). Therefore, the samples were immersed in the epoxy resin and their surfaces were subjected to grinding and polishing procedure. As a result, the borders of air voids can be clearly detectable in the SEM images (Figs. 9b, 10b). Note that, the images are presented in grayscale (GS, values in the range of 0-255), where low GS values (dark spots) indicate an air void space, while high GS values (brighter spots) indicate a solid phase (cement matrix, aggregate). Finally, the air voids space was segmented using binarization procedure (Figs. 9c, 10c) for further analysis.

The preliminary results consist of probability density functions (PDFs) of roundness for the two separated groups of samples' air voids presented in Fig. 11. It can be seen, that in the shape of smaller air voids is closer to ideal circle and while their size is larger, their shape is more distorted. However, this phenomenon is much more visible for sample B30 with the addition of AEA in comparison with the results for sample 0 . Therefore, further analyses should be carried out. Nevertheless, much larger region of interest should be taken into consideration due to the large air voids existence. Note that the analyzed images $(12 \times 12 \mathrm{~mm}, 13,000 \times 13,000 \mathrm{px})$ were acquired by combining 256 separate image files. Moreover, to analyze the 3D air voids network, several or even dozens of cross-sections should be studied, and for each of them the grinding and polishing procedure should be subsequently used. Therefore, the X-ray micro-CT was used for further study.

Considering the above, the exemplary 2D microstructure views of the investigated samples, obtained after 28 days of curing, are shown in Fig. 12. In turn, exemplary 3D reconstructions are presented in Fig. 13. The images are presented in grayscale analogous to the SEM imaging results. The 2D microstructure views presented in Fig. 12 show that airentrainment has a significant effect on the structure of air voids. It is visible that the entrained air voids that appear are not isolated in the microstructure. They are interconnected by the capillary pores that are significantly smaller in size. Also, the highly connected structure of the air voids is visible in Fig. 13. It suggests that most of the air voids are caused by the fact, that the floor screeds were not specially compacted.

The size of the structure of the air voids within the concrete samples was analyzed using volume-equivalent sphere diameter and local structure thickness measures. At first, $D_{\mathrm{eq}}$ was evaluated (Figs. 14, 16a), dividing the air voids into three groups: $D_{\text {eq }}$ in the range of $0.130-0.5 \mathrm{~mm}$ (color red), $D_{\text {eq }}$ in the range of $0.5-1.0 \mathrm{~mm}$ (color green) and $D_{\text {eq }}$ larger than $1.0 \mathrm{~mm}$ (color blue). It can be seen that the air voids are mainly larger than $1.0 \mathrm{~mm}$ and that this group influences the fraction of air voids $\phi$. However, for concretes with AEA,
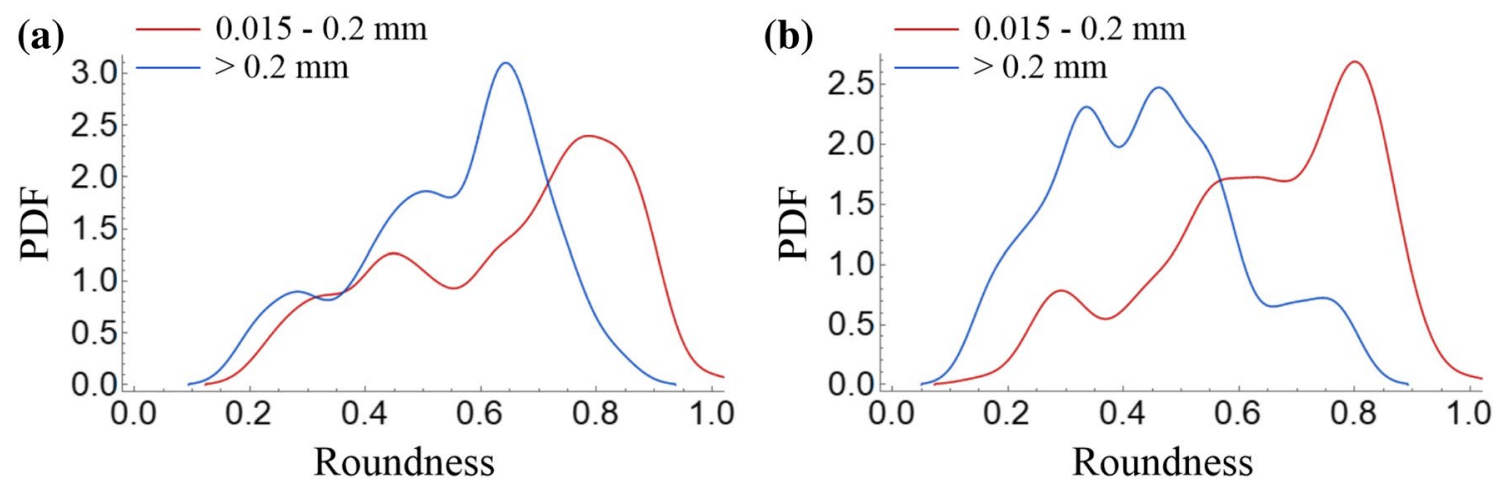

Fig. 11 Probability density functions (PDFs) of roundness for the two separated groups of air voids for sample: $\mathbf{a} 0$ and $\mathbf{b}$ B30
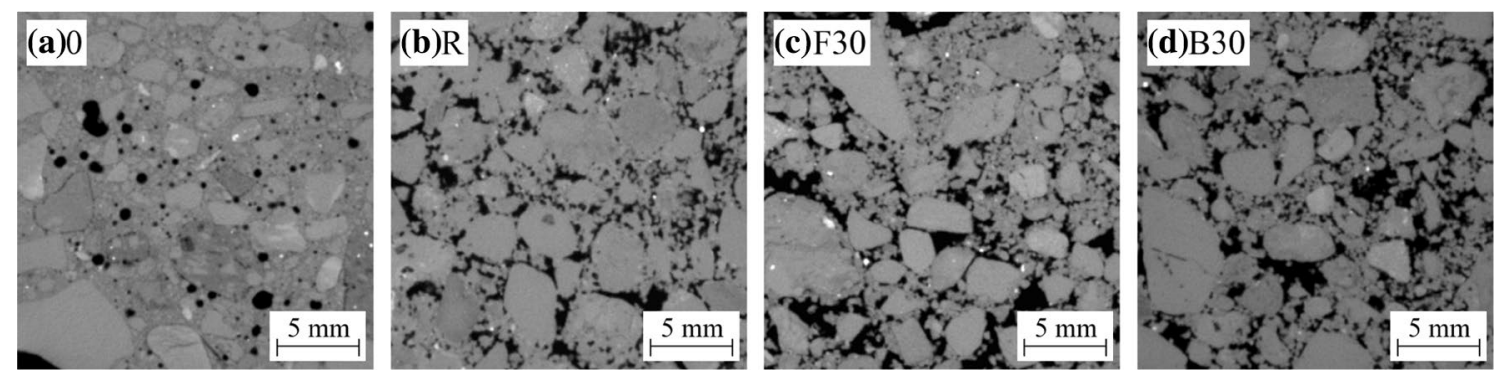

Fig. 12 Exemplary 2D microstructure views obtained using the X-ray micro-CT method for sample: a 0, b R, c F30 and d B30 

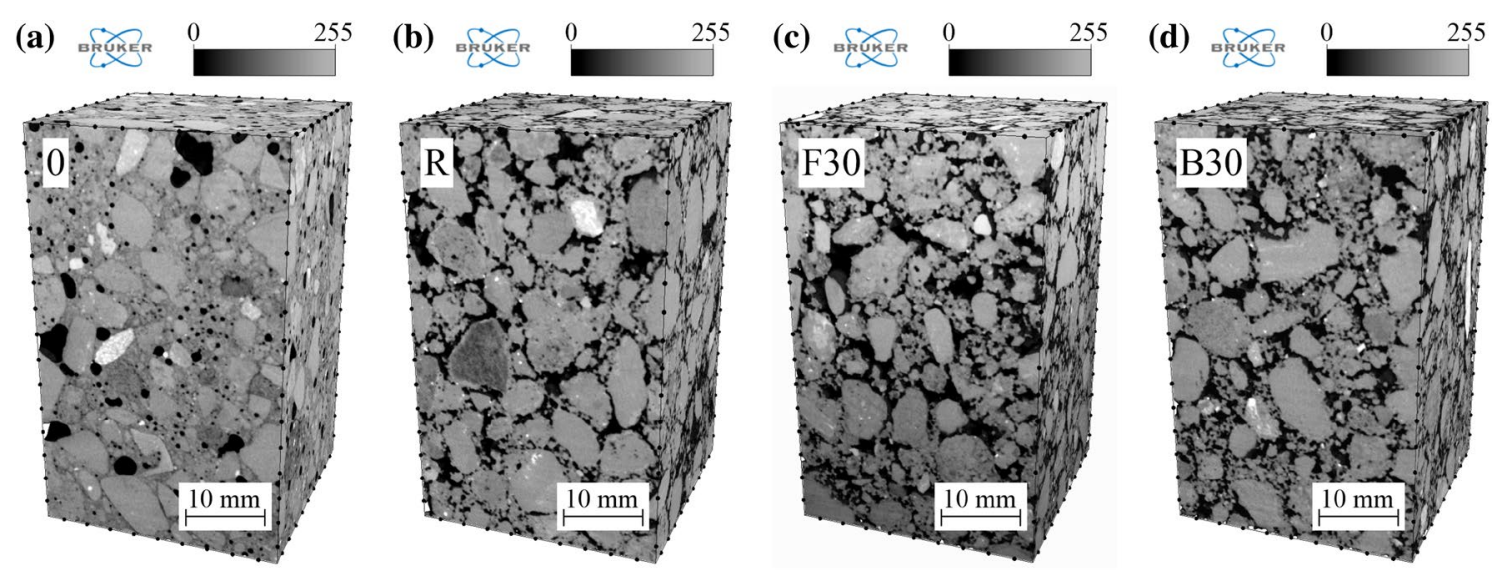

Fig. 13 Exemplary 3D microstructure views obtained using the X-ray micro-CT method for sample: a 0, b R, c F30 and d B30

(a)

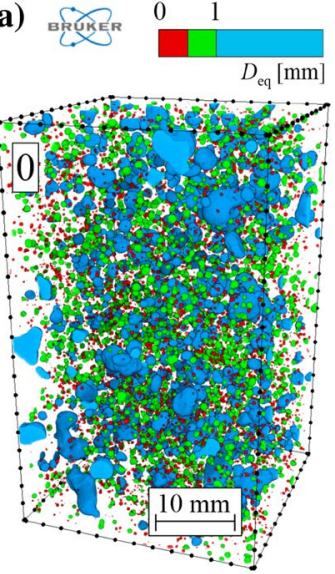

(b)
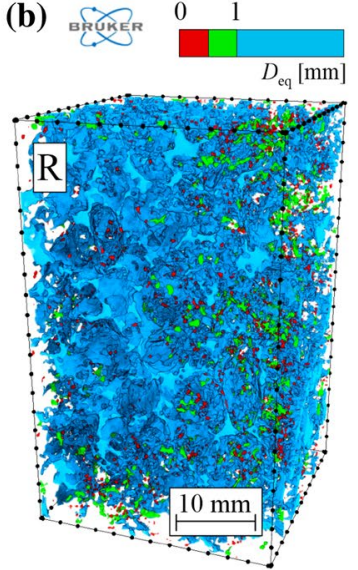

(c)

c) BRUKER

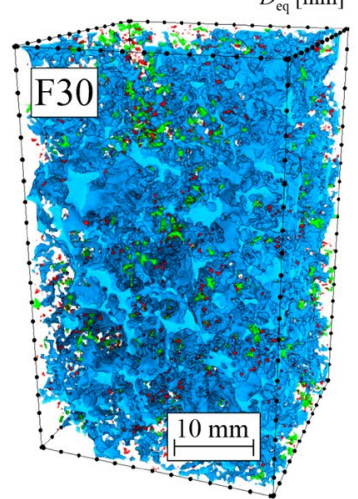

(d)
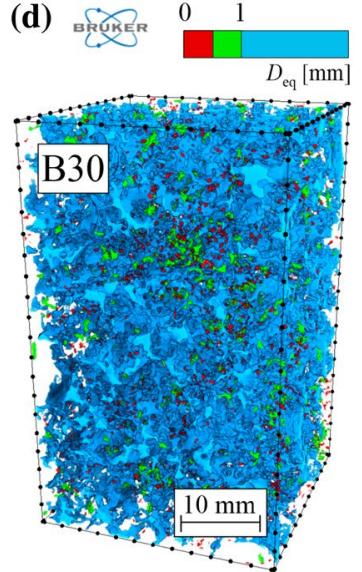

Fig. 14 Exemplary 3D models of the structure of the air voids obtained using X-ray micro-CT and volume-equivalent sphere diameters $D_{\text {eq. }}$. (Color figure online)
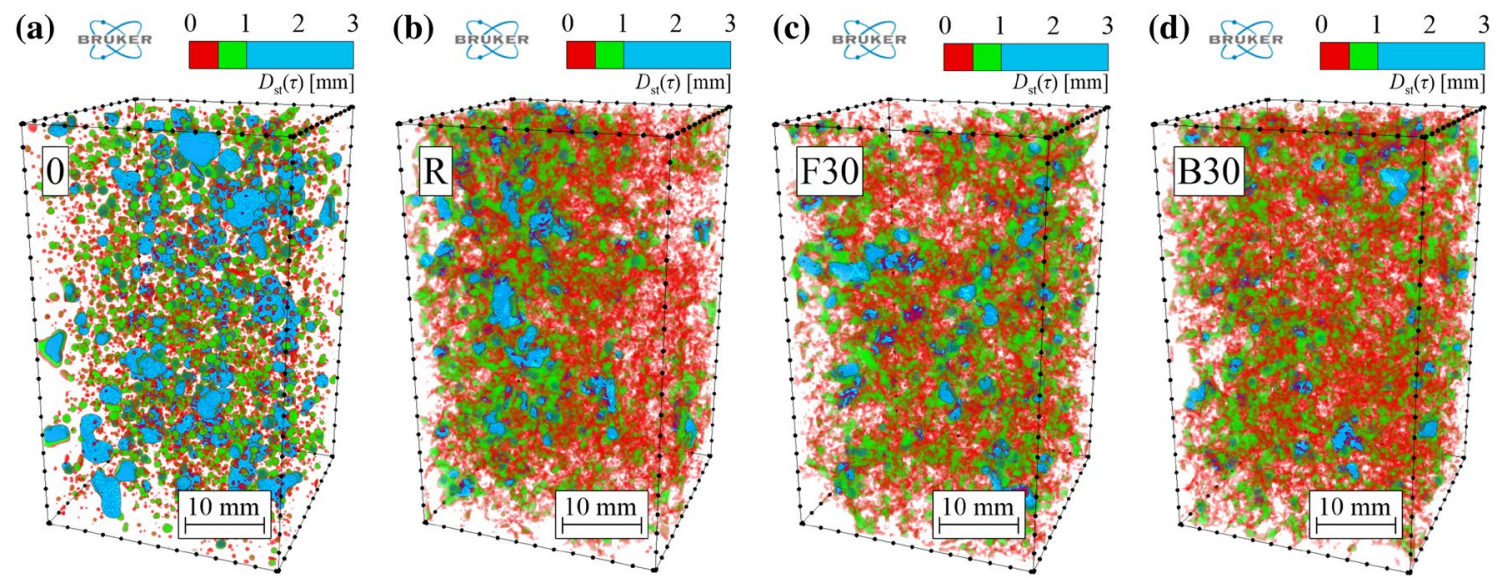

Fig. 15 Exemplary 3D maps of $D_{\mathrm{st}}(\tau)$ for the structure of the air voids obtained using X-ray micro-CT 

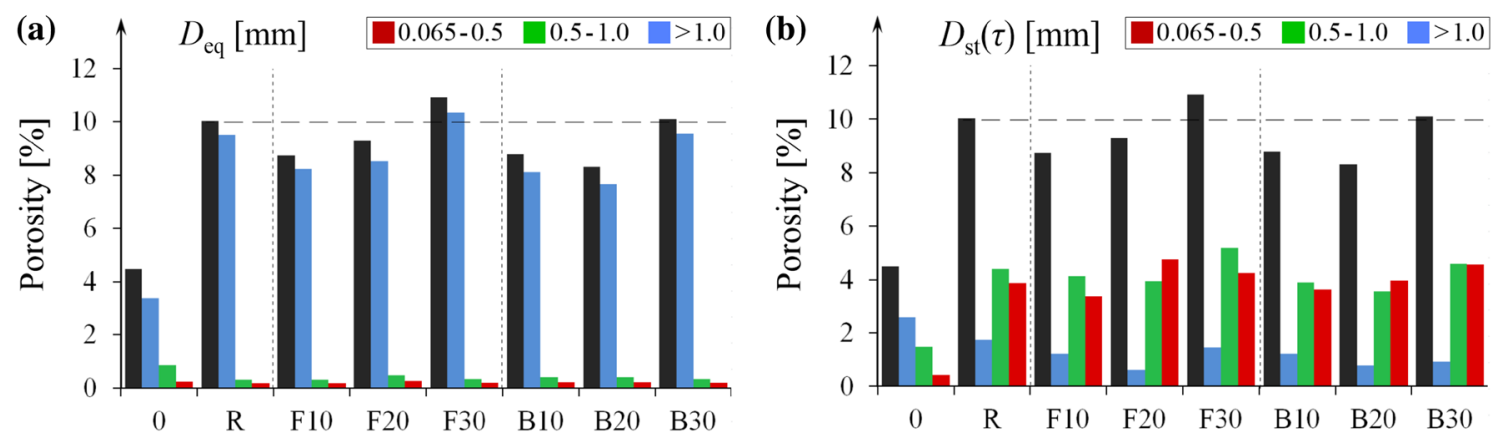

Fig. 16 The volume fraction of air voids for three ranges of air void size evaluated using: a the volume-equivalent sphere diameter $\left(D_{\text {eq }}\right)$, b the local structure thickness $\left[D_{\mathrm{st}}(\tau)\right]$ in comparison to the total fraction of air voids ( $\phi$, black bars). (Color figure online)

the air voids mainly overlap and form complicated porous networks. Thus, $D_{\text {eq }}$ do not give all the important information about the size of the air voids, which is due to e.g., the fact that many small connected air voids are replaced by one large one.

Therefore, the information about the size of the structure of the air voids is supplemented with the $D_{\mathrm{st}}(\tau)$ measurement (Figs. 15, 16b). It can be seen that in the case of reference sample 0 , the results from $D_{\text {eq }}$ and $D_{\text {st }}(\tau)$ are comparable due to the sphericity for all the air void groups being close to perfect spheres (see Fig. 16a). For all the other samples (AEC floor screeds samples), the results for both approaches differ significantly. This is caused, as mentioned before, by the complicated structure of air voids. It can be proved by the sphericity results presented in Fig. 17, which are in the form of PDFs of $\psi$ for the three groups of air voids defined earlier. It can be seen that the larger the air voids are, the more their shape changes from perfect spheres. For all the AEC floor screeds samples, the highest probability of $\psi$ for the smallest air voids is equal to 0.85 , for air voids in the range of $0.5-1.0 \mathrm{~mm}$ it is equal to about 0.62 , and for the largest air voids $(<1 \mathrm{~mm})$ it is less than 0.4 . Note that the sphericity is only evaluated using the volume-equivalent sphere diameter approach. This is due to the fact that the sphericity is evaluated for all single air voids and $D_{\mathrm{st}}(\tau)$ is the density field inside an air void space.

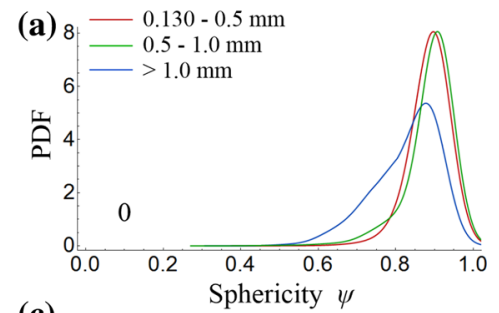

(c)
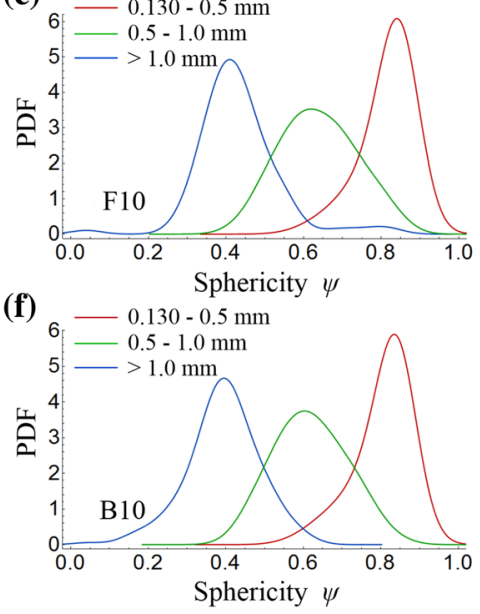

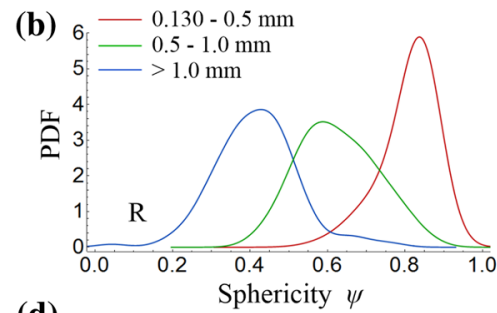

(d)

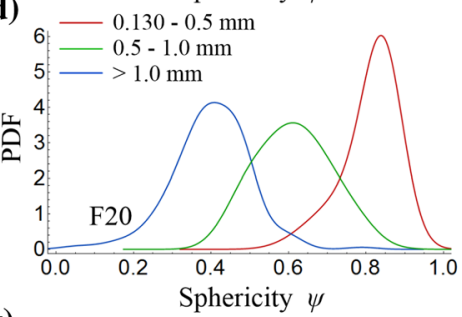

(g)

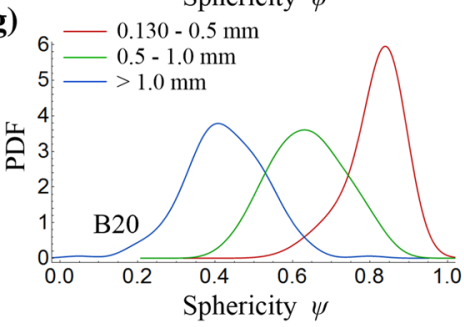

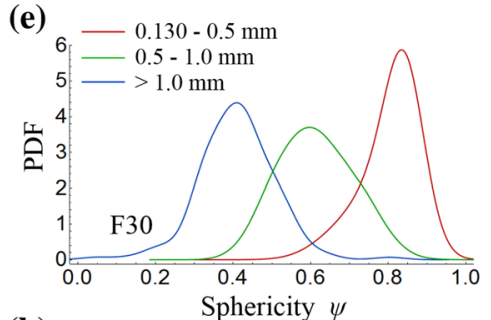

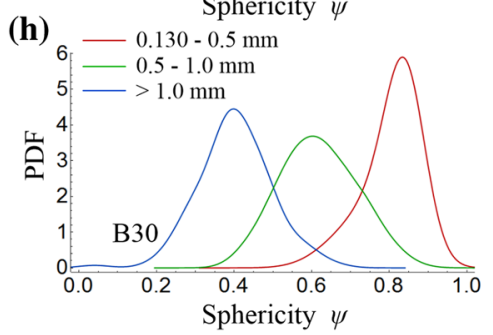

Fig. 17 Probability density functions (PDFs) of sphericity $(\psi)$ for the three separated groups of air voids (in specific range of $D_{\text {eq }}$ values) for sample: a 0, b R, c F10, d F20, e F30, f B10, g B20 and h B30 
Additionally, Fig. 9 presents the total fraction of air voids $\phi$ evaluated with the use of X-ray micro-CT (black bars). The standard deviation of the porosity (evaluated for the porosity in each cross-section of the VOI) varies between $1.24 \%$ and $1.49 \%$ for all samples (except sample 0 for which the standard deviation of the porosity is equal to $0.86 \%$ ). It results in the coefficient of variation on the level of $12-15 \%$ (and 19\% for sample 0). It is visible from Fig. 12, that the reference concrete had a total fraction of air voids about $10 \%$. Typically the air-entrained concrete for frost protection has total air content of around 4-6\%. The remaining part of the air voids may be the result of the fact that the floor screeds samples were not compacted, but only patch grabbed as usually in the case of floor screeds. The results of the fraction of air voids indicate that the addition of $10 \%$ and $20 \%$ quartz-feldspar and basalt powders sourced from industrial wastes decreases the fraction of air voids (for air voids larger than $130 \mu \mathrm{m}$ ) for the AEC floor screeds samples. However, for the air voids larger than $130 \mu \mathrm{m}$ the addition of $30 \%$ of used mineral powders increases the fraction of air voids $\phi$ in comparison to sample R. This may suggest the limit for the effective use of quartz-feldspar and basal mineral powders of about $20 \%$ of mass of the binder. A similar limit for the effective use of mineral powders in AEC floor screeds was also found for ceramic powders [67]. However, the size of particles of cement and powders are very close to each other (see Fig. 3). This may suggest that the mechanism of the creation of air voids structure results from the difference in chemical composition of cement and powders.

Based on Fig. 16b, it can be noticed that for all the AEC floor screeds samples the fraction of air voids larger than $1 \mathrm{~mm}$ is lower, in comparison to sample 0 , by about $32 \%$ for R sample, $43-76 \%$ for samples F10-F30 and $52-70 \%$ for samples B10-B30. However, the fraction of air voids for smaller air voids is much higher for the AEC floor screeds samples by about $140-250 \%$ for air voids in the range of $0.5-1.0 \mathrm{~mm}$, and by about $700-1000 \%$ for air voids in the range of $0.130-0.5 \mathrm{~mm}$. This coincides with Standard ASTM C 125, which specifies the diameter of typical entrained air voids to be in the range of $0.010-1.0 \mathrm{~mm}$.

\section{Final Conclusions and Perspectives}

In the approach presented in the article, microstructural tests were performed in order to study the structure of air voids in AEC floor screeds that contains mineral powders sourced from industrial wastes. Based on the presented research, the following conclusions can be drawn:

- The results presented in this work confirm the potential of X-ray micro-CT to observe the air voids structure in low-strength AEC floor screeds that contains mineral powders sourced from industrial wastes. A simple methodology was illustrated. If carefully applied, the procedure provides a useful tool for this purpose. As expected, the obtained by X-ray micro-CT values of the fraction of the air voids are lower than the total porosity measured by the water absorption. As pointed out in [50] it is due to the fact that the water absorption method allow to determine all air voids, while in this case X-ray micro-CT visualizes voids larger than $130 \mu \mathrm{m}$. Thus, the X-ray micro-CT analysis can be used only as an indication rather than accurate elemental analysis of the effect of air-entrainment on the structure of air voids in AEC modified by waste mineral powders.

- AEA significantly changes the structure of the air void space of AEC floor screeds. Its addition to concrete results in an increase of the fraction of air voids and its overlap. However, its addition can also result in a reduction of the thickness of the local structure of an air void's space (see Fig. 13a),

- in the case of AEC floor screeds, where many air voids overlap and form complicated porous networks, measurement of the thickness of the local structure can be useful for the investigation of the size of air voids. The highly connected structure of the air voids suggests also that most of the air voids are caused by the fact, that the floor screeds were not specially compacted,

- the addition of quartz-feldspar and basalt powders has negative effect on the performance of AEC floor screeds. It reduces the compressive and tensile strength of AEC floor screeds. the reduction of the fraction of air voids (for air voids larger than $130 \mu \mathrm{m}$ ) in AEC floor screeds is also negative with respect to air-entrained concretes. This may suggest that the mechanism of the creation of air voids structure results from the difference in chemical composition of cement and powders,

- no significant changes in the structure of air void space were noticed in AEC floor screeds with the addition of mineral powders in the range between 10-30\%, except for a slight difference in the total fraction of air voids.

Concerning the practical implications for the work the general conclusion is that the incorporation of mineral powders sourced from industrial wastes may be beneficial. The properties of low-strength AEC floor screeds may be acceptable, for the sake of the fact that it allows to reduce the waste, save natural resources and consequently reduce greenhouse gases emissions. Thus, the proposed way of utilization of the waste mineral powder has got the potential to obtain an economically sensible product in the form of sustainable concrete floor screeds. However, The presented results merit further investigation. Further work on the effect of AEA on other properties of AEC floor screeds is currently ongoing. 
Estimation of the macro properties of concrete can be made using, among other methods, approximation homogenization schemes, e.g., Mori-Tanaka scheme [68]. For this purpose, a proper assumption of the microstructure morphology (e.g., shape of inclusions) is crucial. However, the shape of pores of concrete is usually assumed a priori as a spherical one (see e.g., [69]). The results presented in the article shows, that in the case of low-strength AEC, the aforementioned assumption would not be legitimate. Therefore, the shape of pores evaluated using X-ray micro-CT method together with the principal components analysis [70] should be used in this case to the identify the necessary input data for the macro properties estimation using, e.g., Mori-Tanaka scheme.

Acknowledgements The authors would like to acknowledge the support of Andrzej Żak from the Faculty of Mechanical Engineering (Wroclaw University of Science and Technology) for all aspects and facilities that enabled the SEM analysis to be performed. The measurements using micro-CT were conducted at the Centre of Engineering Studies of the State School of Higher Education (Pol. PWSZ) in Chełm within the project "Laboratory of Environmental Studies CSI PWSZ in Chełm," co-financed by the European Fund of Regional Development (part of the Operational Programme Eastern Poland) 2007-2013.

\section{Compliance with Ethical Standards}

Conflict of interest The authors declare no conflict of interest. The founding sponsors had no role in the design of the study; in the collection, analyses, or interpretation of data; in the writing of the manuscript, and in the decision to publish the results.

Open Access This article is distributed under the terms of the Creative Commons Attribution 4.0 International License (http://creativeco mmons.org/licenses/by/4.0/), which permits unrestricted use, distribution, and reproduction in any medium, provided you give appropriate credit to the original author(s) and the source, provide a link to the Creative Commons license, and indicate if changes were made.

\section{References}

1. Liu, K., Yan, J., Hu, Q., Sun, Y., Zou, C.: Effects of parent concrete and mixing method on the resistance to freezing and thawing of air-entrained recycled aggregate concrete. Constr. Build. Mater. 106, 264-273 (2016)

2. Czarnecki, L., van Gemert, D.: Innovation in construction materials engineering versus sustainable development. Bull. Pol. Acad. Sci. Tech. Sci. 65(6), 765-771 (2017)

3. Zobal, O., Holčapek, O., Reiterman, P.: Frost resistance of concrete screed with the fly ash addition. Key Eng. Mater. 677, 80-85 (2016)

4. Galetakis, M., Soultana, A.: A review on the utilisation of quarry and ornamental stone industry fine by-products in the construction sector. Constr. Build. Mater. 102, 769-781 (2016)

5. Safiuddin, M., Raman, S.N., Zain, M.F.M.: Utilization of quarry waste fine aggregate in concrete mixtures. J. Appl. Sci. Res. 3(3), 202-208 (2007)
6. Sangiorgi, C., Tataranni, P., Mazzotta, F., Simone, A., Vignali, V., Lantieri, C.: Alternative fillers for the production of bituminous mixtures: a screening investigation on waste powders. Coatings 7(6), 76 (2017)

7. Hesami, S., Modarres, A., Soltaninejad, M., Madani, H.: Mechanical properties of roller compacted concrete pavement containing coal waste and limestone powder as partial replacements of cement. Constr. Build. Mater. 111, 625-636 (2016)

8. Singh, M., Srivastava, A., Bhunia, D.: An investigation on effect of partial replacement of cement by waste marble slurry. Constr. Build. Mater. 134, 471-488 (2017)

9. Belaidi, A.S.E., Kenai, S., Kadri, E.H., Soualhi, H., Benchaâ, B.: Effects of experimental ternary cements on fresh and hardened properties of self-compacting concretes. J. Adhes. Sci. Technol. 30(3), 247-261 (2016)

10. Marinković, S., Dragaš, J., Ignjatović, I., Tošić, N.: Environmental assessment of green concretes for structural use. J. Clean. Prod. 154, 633-649 (2017)

11. Hawileh, R.A., Abdalla, J.A., Fardmanesh, F., Shahsana, P., Khalili, A.: Performance of reinforced concrete beams cast with different percentages of GGBS replacement to cement. Arch. Civil Mech. Eng. 17(3), 511-519 (2017)

12. Fontes, C.M.A., Silva, R.B., Lima, P.R.L.: Characterization and effect of using bottom and fly ashes from co-combustion of cocoa waste as mineral addition in concrete. Waste Biomass Valoriz. (2017). https://doi.org/10.1007/s12649-017-0031-x

13. Ong, S.K., Mo, K.H., Alengaram, U.J., Jumaat, M.Z., Ling, T.C.: Valorization of wastes from power plant, steel-making and palm oil industries as partial sand substitute in concrete. Waste Biomass Valoriz. 9, 1-10 (2017)

14. Nagrockienè, D., Girskas, G., Skripkiūnas, G.: Properties of concrete modified with mineral additives. Constr. Build. Mater. 135, 37-42 (2017)

15. Rafiei, M.H., Adeli, H.: Sustainability in highrise building design and construction. Struct. Des. Tall Spec. Build. 25(13), 643-658 (2016)

16. Bergmans, J., Nielsen, P., Snellings, R., Broos, K.: Recycling of autoclaved aerated concrete in floor screeds: Sulfate leaching reduction by ettringite formation. Constr. Build. Mater. 111, 9-14 (2016)

17. Moreira, A., António, J., Tadeu, A.: Lightweight screed containing cork granules: mechanical and hygrothermal characterization. Cem. Concr. Compos. 49, 1-8 (2014)

18. Czarnecki, L., Woyciechowski, P., Adamczewski, G.: Risk of concrete carbonation with mineral industrial by-products. KSCE J. Civil Eng. 22, 1-10 (2017)

19. Tikkanen, J., Penttala, V., Ćwirzeń, A.: Mineral powder concrete-effects of powder content on concrete properties. Mag. Concr. Res. 63(12), 893-903 (2011)

20. Tikkanen, J., Ćwirzeń, A., Penttala, V.: Freeze-thaw resistance of normal strength powder concretes. Mag. Concr. Res. 67(2), 71-81 (2015)

21. Tikkanen, J.: Effects of mineral powders on hydration process and hydration products in normal strength concrete. Constr. Build. Mater. 72, 7-14 (2014)

22. Popek, M., Sadowski, Ł, Szymanowski, J.: Abrasion resistance of concrete containing selected mineral powders. Proc. Eng. 153, 617-622 (2016)

23. Tayeh, B.A., Abu Bakar, B.H., Megat Johari, M.A., Zeyad, A.M.: Microstructural analysis of the adhesion mechanism between old concrete substrate and UHPFC. J. Adhes. Sci. Technol. 28(18), 1846-1864 (2014)

24. Wong, H.S., Pappas, A.M., Zimmerman, R.W., Buenfeld, N.R.: Effect of entrained air voids on the microstructure and mass transport properties of concrete. Cem. Concr. Res. 41(10), 1067-1077 (2011) 
25. Bogas, J.A., De Brito, J., Ramos, D.: Freeze-thaw resistance of concrete produced with fine recycled concrete aggregates. J. Clean. Prod. 115, 294-306 (2016)

26. Ramezanianpour, A.A., Mohammadi, A., Dehkordi, E.R., Chenar, Q.B.: Mechanical properties and durability of roller compacted concrete pavements in cold regions. Constr. Build. Mater. 146, 260-266 (2017)

27. Rath, S., Puthipad, N., Attachaiyawuth, A., Ouchi, M.: Critical size of entrained air to stability of air volume in mortar of selfcompacting concrete at fresh stage. J. Adv. Concr. Technol. 15(1), 29-37 (2017)

28. Dąbrowski, M., Glinicki, M.A., Gibas, K., Jóźwiak-Niedźwiedzka, D.: Effects of calcareous fly ash in blended cements on chloride ions migration and strength of air entrained concrete. Constr. Build. Mater. 126, 1044-1053 (2016)

29. Šeputytė-Jucikè, J., Kligys, M.: The effects of modifying additives and chemical admixtures on the properties of porous fresh and hardened cement paste. Constr. Build. Mater. 127, 679-691 (2016)

30. Puthipad, N., Ouchi, M., Rath, S., Attachaiyawuth, A.: Enhanced entrainment of fine air bubbles in self-compacting concrete with high volume of fly ash using defoaming agent for improved entrained air stability and higher aggregate content. Constr. Build. Mater. 144, 1-12 (2017)

31. Piasta, W., Sikora, H.: Effect of air entrainment on shrinkage of blended cements concretes. Constr. Build. Mater. 99, 298-307 (2015)

32. Guo, S., Dai, Q., Sun, X., Sun, Y., Liu, Z.: Ultrasonic techniques for air void size distribution and property evaluation in both earlyage and hardened concrete samples. Appl. Sci. 7(3), 290 (2017)

33. ASTM, C.: 457-82a. Standard Practice for Microscopical Determination of Air-Void Content and Parameters of the Air-Void System in Hardened Concrete, ASTM (1982)

34. ASTM, C. 125 Standard Terminology Relating to Concrete and Concrete Aggregates. Annual Book of ASTM Standards (2003)

35. Łaźniewska-Piekarczyk, B.: The influence of admixtures type on the air-voids parameters of non-air-entrained and air-entrained high performance SCC. Constr. Build. Mater. 41, 109-124 (2013)

36. Hubler, M.H., Gelb, J., Ulm, F.J.: Microtexture analysis of gas shale by XRM imaging. J. Nanomech. Micromech. 7(3), 04017005 (2017)

37. Parisatto, M., Dalconi, M.C., Valentini, L., Artioli, G., Rack, A., Tucoulou, R., et al.: Examining microstructural evolution of Portland cements by in-situ synchrotron micro-tomography. J. Mater. Sci. 50(4), 1805-1817 (2015)

38. Kashani, A., Ngo, T.D., Mendis, P., Black, J.R., Hajimohammadi, A.: A sustainable application of recycled tyre crumbs as insulator in lightweight cellular concrete. J. Clean. Prod. 149, 925-935 (2017)

39. Cnudde, V., Cnudde, J.P., Dupuis, C., Jacobs, P.J.S.: X-ray micro$\mathrm{CT}$ used for the localization of water repellents and consolidants inside natural building stones. Materials characterization 53(2-4), 259-271 (2004)

40. Rheinheimer, V., Wu, Y., Wu, T., Celik, K., Wang, J., De Lorenzis, L., et al.: Multi-scale study of high-strength low-thermalconductivity cement composites containing cenospheres. Cem. Concr. Compos. 80, 91-103 (2017)

41. Kashkarov, E., Nikitenkov, N., Sutygina, A., Laptev, R., Bordulev, Y., Obrosov, A., Liedke, M.O., Wagner, A., Zak, A., Wei $\beta$, S.: Microstructure, defect structure and hydrogen trapping in zirconium alloy $\mathrm{Zr}-1 \mathrm{Nb}$ treated by plasma immersion Ti ion implantation and deposition, J. Alloys Compd. 732, 80-87 (2018)

42. Chung, S.Y., Abd Elrahman, M., Sikora, P., Rucinska, T., Horszczaruk, E., Stephan, D.: Evaluation of the effects of crushed and expanded waste glass aggregates on the material properties of lightweight concrete using image-based approaches. Materials 10(12), 1354 (2017)
43. Kupwade-Patil, K., Palkovic, S.D., Bumajdad, A., Soriano, C., Büyüköztürk, O.: Use of silica fume and natural volcanic ash as a replacement to Portland cement: micro and pore structural investigation using NMR, XRD, FTIR and X-ray microtomography. Constr. Build. Mater. 158, 574-590 (2018)

44. Li, W., Pour-Ghaz, M., Trtik, P., Wyrzykowski, M., Münch, B., Lura, P., et al.: Using neutron radiography to assess water absorption in air entrained mortar. Constr. Build. Mater. 110, 98-105 (2016)

45. Chung, S.Y., Elrahman, M.A., Stephan, D., Kamm, P.H.: Investigation of characteristics and responses of insulating cement paste specimens with Aer solids using X-ray micro-computed tomography. Constr. Build. Mater. 118, 204-215 (2016)

46. Stock, S.R.: Recent advances in X-ray microtomography applied to materials. Int. Mater. Rev. 53(3), 129-181 (2008)

47. Rajczakowska, M., Stefaniuk, D., Łydżba, D.: Microstructure characterization by means of X-ray micro-CT and nanoindentation measurements. Studia Geotech. Mech. 37(1), 75-84 (2015)

48. Wieczorowski, M., Gapinski, B.: X-ray CT in metrology of geometric feature. Acta Techni. Corviniensis-Bull. Eng. 7(1), 95 (2014)

49. Ponikiewski, T., Katzer, J., Bugdol, M., Rudzki, M.: Determination of 3D porosity in steel fibre reinforced SCC beams using X-ray computed tomography. Constr. Build. Mater. 68, 333-340 (2014)

50. Cnudde, V., Cwirzen, A., Masschaele, B., Jacobs, P.J.S.: Porosity and microstructure characterization of building stones and concretes. Eng. Geol. 103(3), 76-83 (2009)

51. Du Plessis, A., Olawuyi, B.J., Boshoff, W.P., Le Roux, S.G.: Simple and fast porosity analysis of concrete using X-ray computed tomography. Mater. Struct. 49, 1-10 (2014)

52. Bywalski, C., Rajczakowska, M., Sadowski, Ł: Barrage lock concrete porosity evaluation using X-ray microtomography. Key Eng. Mater. 662, 161-164 (2015)

53. Ponikiewski, T., Katzer, J., Bugdol, M., Rudzki, M.: Steel fibre spacing in self-compacting concrete precast walls by X-ray computed tomography. Mater. Struct. 48(12), 3863-3874 (2015)

54. Leite, M.B., Monteiro, P.J.M.: Microstructural analysis of recycled concrete using X-ray microtomography. Cem. Concr. Res. 81, 38-48 (2016)

55. Kim, K.Y., Yun, T.S., Park, K.P.: Evaluation of pore structures and cracking in cement paste exposed to elevated temperatures by X-ray computed tomography. Cem. Concr. Res. 50, 34-40 (2013)

56. Chung, S.Y., Lehmann, C., Abd Elrahman, M., Stephan, D.: Pore characteristics and their effects on the material properties of foamed concrete evaluated using micro-CT images and numerical approaches. Appl. Sci. 7(6), 550 (2017)

57. Lu, H., Alymov, E., Shah, S., Peterson, K.: Measurement of air void system in lightweight concrete by X-ray computed tomography. Constr. Build. Mater. 152, 467-483 (2017)

58. http://www.sksm.pl. Accessed 29 Dec 2017)

59. http://www.bazalt.pl/. Accessed 29 Dec 2017

60. Różański, A., Rajczakowska, M., Serwicki, A.: The influence of microstructure geometry on the scale effect in mechanical behaviour of heterogeneous materials. Sci. Eng. Compos. Mater. 24(4), 557-571 (2017)

61. Iassonov, P., Gebrenegus, T., Tuller, M.: Segmentation of X-ray computed tomography images of porous materials: A crucial step for characterization and quantitative analysis of pore structures. Water Resour. Res. (2009). https://doi.org/10.1029/2009WR0080 87

62. Hildebrand, T., Rüegsegger, P.: A new method for the modelindependent assessment of thickness in three-dimensional images. J Microsc. 185(1), 67-75 (1997) 
63. Ulrich, D., Van Rietbergen, B., Laib, A., Ruegsegger, P.: The ability of three-dimensional structural indices to reflect mechanical aspects of trabecular bone. Bone 25(1), 55-60 (1999)

64. Canbaz, M., Topçu, İB., Ateşin, Ö: Effect of admixture ratio and aggregate type on self-leveling screed properties. Constr. Build. Mater. 116, 321-325 (2016)

65. Wadell, H.: Volume, shape, and roundness of quartz particles. J. Geol. 43(3), 250-280 (1935)

66. Jones, A.C., Arns, C.H., Sheppard, A.P., Hutmacher, D.W., Milthorpe, B.K., Knackstedt, M.A.: Assessment of bone ingrowth into porous biomaterials using MICRO-CT. Biomaterials 28(15), 2491-2504 (2007)

67. Kulovana, T., Vejmelkova, E., Keppert, M., Rovnanikova, P., Ondráček, M., Keršner, Z., Černý, R.: Air-entrained concrete technology as an effective tool for increasing the limits of brick powder percentage in blended Portland cement binders. Cem. Wapno Beton 1, 11-24 (2015)

68. Mori, T., Tanaka, K.: Average stress in matrix and average elastic energy of materials with misfitting inclusions. Acta Metall. 21(5), 571-574 (1973)

69. Sorelli, L., Constantinides, G., Ulm, F.J., Toutlemonde, F.: The nano-mechanical signature of ultra high performance concrete by statistical nanoindentation techniques. Cem. Concr. Res. 38(12), 1447-1456 (2008)

70. Kalo, K., Grgic, D., Auvray, C., Giraud, A.: Microstructural characterization of oolitic rocks and numerical evaluation of their effective elastic properties. Proc. Eng. 191, 59-66 (2017) 